Loss Aversion in Aggregate Macroeconomic Time Series

Rina Rosenblatt-Wisch

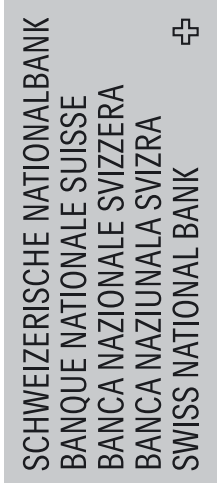

O

(4)

(1)

ro

(

$\frac{0}{\frac{1}{2}}$

re

e

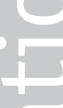

ro 
The views expressed in this paper are those of the author(s) and do not necessarily represent those of the Swiss National Bank. Working Papers describe research in progress. Their aim is to elicit comments and to further debate.

ISSN $1660-7716$

๑ 2007 by Swiss National Bank, Börsenstrasse 15, P.0. Box, CH-8022 Zurich 


\title{
Loss Aversion in Aggregate Macroeconomic Time Series*
}

\author{
Rina Rosenblatt-Wisch ${ }^{\mathrm{a}}$ \\ First Version: July 2005 \\ Current Version: August 2006
}

\begin{abstract}
Prospect theory has been the focus of increasing attention in many fields of economics. However, it has scarcely been addressed in macroeconomic growth models - neither on theoretical nor on empirical grounds. In this paper we use prospect theory in a stochastic optimal growth model. Thereafter, the focus lies on linking the Euler equation obtained from a prospect theory growth model of this kind to real macroeconomic data. We will use Generalized Method of Moments (GMM) estimation to test the implications of such a non-linear prospect utility Euler equation. Our results indicate that loss aversion can be traced in aggregate macroeconomic time series.
\end{abstract}

JEL-Classification: E21; O41.

Keywords: Ramsey growth model; loss aversion; prospect theory; GMM.

${ }^{*}$ The views expressed in this paper are those of the author and do not necessarily represent those of the Swiss National Bank. I would like to thank Thorsten Hens, Peter Woehrmann, Josef Zweimüller, participants of the $14^{\text {th }}$ Symposium of the Society for Nonlinear Dynamics and Econometrics and an anonymous referee for helpful comments. Part of this research has been carried out within the national centre of competence in research, "Financial Valuation and Risk Management", and financial support is gratefully acknowledged. The national centres in research are managed by the Swiss National Science Foundation on behalf of the federal authorities.

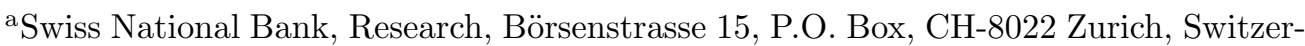
land.

Email: rina.rosenblatt@snb.ch 


\section{Introduction}

In this paper, our aim is to establish a link between the increasingly weighty empirical evidence indicating people's unwillingness to fit the classical description of the homo economicus and a stochastic version of the CassKoopmans-Ramsey optimal growth model, Cass (1965), Koopmans (1965), Ramsey (1928). With this in mind, we study an optimal growth model with a representative agent whose preferences are given by the experimentally validated prospect utility function of Kahneman and Tversky (1979/ 1992). Their prospect theory builds inter alia on the evidence that economic agents value their prospects in gains and losses relative to a reference point and that losses loom larger than gains.

The first order conditions of such an optimal growth model with a prospect utility maximizer differ from the standard model where preferences are timeseparable. To validate the prospect utility Euler equation, we link it to real macroeconomic data using GMM estimation - an estimation procedure for Euler equations introduced by Hansen and Singleton (1982). The paper suggests a reconciliation between prospect theory, in particular loss aversion and reference point dependence, and aggregate macroeconomic time series data.

Growth models in which agents' utility functions are non-standard and/ or current utility also depends on past consumption have been considered for quite some time. Ryder and Heal (1973), Boyer (1978) and recently AlonsoCarrera et al. (2005) allow for habit formation, Laibson (1997) and Barro (1999) study hyperbolic discounting, Koopmans (1960), Uzawa (1968) and, more recently, Mausumi (2003) deal with recursive preferences and marginal impatience, Shi and Epstein (1993) incorporate recursive preferences and habit formation, and De la Croix and Michel (1999) study optimal growth under hereditary tastes. However, none of these explores the prospect utility point of view.

Kahneman and Tversky's prospect theory has already found wide application in conjunction with financial markets and individual portfolio choices. Although prospect theory is based, first and foremost, on individual behavior under uncertainty, it is worth questioning whether the concept of loss aversion could also hold at the aggregate level. Tracing loss aversion in business cycle data could have implications for macroeconomic modelling, and, in particular, for the assumptions made about the behavior of representative agents.

The paper is organized as follows: In the next section of the paper the 
model is set up and the stochastic prospect utility Euler equation is derived. The next steps focus on validating this Euler equation with real data. To this end, a method is developed to convert the stochastic Euler equation into a form suitable for GMM estimation. We then present the results of the estimation, before summarizing and concluding the paper.

\section{The Model}

\subsection{A Prospect Utility Function}

Inspired by Kahneman and Tversky's (1979/1992) prospect theory, we will focus on a non-time-separable utility function. For this utility function we will derive a stochastic Euler equation and convert it into a form that allows us to apply GMM. The prospect utility Euler equation incorporates loss aversion and we will test whether loss aversion can be found in macroeconomic time series.

In Kahneman and Tversky's prospect theory (1979/1992), agents value their prospects in terms of gains and losses relative to a reference point. They are loss averse, which means that they are more averse to losses than gain seeking on the other hand. Furthermore, they perform subjective, nonlinear probability transformations whereby they allot higher weights to small probabilities and allot lower weights to high probabilities. Kahneman and Tversky suggest a value function which is concave in the region of gains and convex for losses. To capture the effect of loss aversion it is steeper in the region of losses. Based on this approach, Kahneman and Tversky (1992) specify the following two-part value power function: :

$$
v(x)= \begin{cases}x^{\hat{\alpha}} & \text { if } x \geq 0 \\ -\lambda(-x)^{\hat{\beta}} & \text { if } x<0\end{cases}
$$

where $x$ represents a gain or a loss and $\lambda>1$ captures loss aversion indicating the fact that losses hurt more than gains. In an experiment, Kahneman and Tversky (1992) estimated the following values for the parameters: $\hat{\alpha}=\hat{\beta}=$ 0.88 and $\lambda=2.25$.

Under cumulative prospect theory the value $V$ of a lottery is evaluated as a weighted average of the following form: ${ }^{1}$

\footnotetext{
${ }^{1}$ See Polkovnichenko (2003).
} 


$$
V=\sum_{i \in \text { gains }} w_{i}^{+} v\left(x_{i}\right)+\sum_{i \in \text { losses }} w_{i}^{-} v\left(x_{i}\right)
$$

where the decision weights $w$ are not the objective probabilities of the lottery, but are calculated by using the following functional form:

$$
w^{+}(\pi)=\frac{\pi^{\hat{\gamma}}}{\left(\pi^{\hat{\gamma}}+(1-\pi)^{\hat{\gamma}}\right)^{\frac{1}{\hat{\gamma}}}}, \quad w^{-}(\pi)=\frac{\pi^{\hat{\delta}}}{\left(\pi^{\hat{\delta}}+(1-\pi)^{\hat{\delta}}\right)^{\frac{1}{\hat{\delta}}}}
$$

with $\hat{\gamma}$ estimated to be 0.61 and $\hat{\delta}$ to be 0.69 . The decision weights are calculated as $w_{i}^{ \pm}=w^{ \pm}\left(\pi_{i}\right)-w^{ \pm}\left(\pi_{i^{*}}\right)$ where $\pi_{i^{*}}$ is the probability of the outcomes that are strictly better (worse) than $i$, and $\pi_{i}$ on the other hand is the probability of all outcomes at least as good (bad) as $i$.

In this study we focus on loss aversion and assume that the agent generates utility out of differences. We therefore suggest a linear value function for losses and gains with a kink at the reference point. Losses and gains are negative or positive changes in consumption relative to a reference point. The piecewise-linear approximation is a common approach, being used, for example, by Aït-Sahalia and Brandt (2001) to derive an asset pricing Euler equation, which is then used for GMM estimation.

Hence, we define a piecewise-linear prospect utility function:

$$
u\left(\Delta c_{t}\right)= \begin{cases}\Delta c_{t} & \text { if } \Delta c_{t} \geq 0 \\ \lambda \Delta c_{t} & \text { if } \Delta c_{t}<0\end{cases}
$$

where $\Delta c_{t}=c_{t}-c_{t-1}$. Also, $\lambda>1$ to capture loss aversion.

Note that:

- $\frac{\partial u\left(\Delta c_{t}\right)}{\partial \Delta c_{t}}>0$ for $\Delta c_{t} \neq 0$

- $\frac{\partial u\left(\Delta c_{t}\right)}{\partial \Delta c_{t}}<\frac{\partial u\left(-\Delta c_{t}\right)}{\partial\left(-\Delta c_{t}\right)}$.

The social planner ${ }^{2}$ solves

$$
\max _{\Delta c_{t}, k_{t+1}} E \sum_{t=0}^{\infty} \beta^{t} u\left(\Delta c_{t}\right)
$$

\footnotetext{
${ }^{2}$ Markets are complete and agents behave competitively so that the First Fundamental Theorem of Welfare Economics holds.
} 
subject to the constraint

$$
f\left(k_{t}\right)+(1-\delta) k_{t}=c_{t}+k_{t+1},
$$

where the production function $f\left(k_{t}\right)$ is strictly increasing and concave and the production shocks $A_{t}$ (introduced later) are assumed to enter into the production function in a multiplicative manner. $\beta$ is the discount factor and $0<\beta<1$.

$\Delta c_{t}$ can be expressed as

$$
\Delta c_{t}=f\left(k_{t}\right)+(1-\delta) k_{t}-k_{t+1}-f\left(k_{t-1}\right)-(1-\delta) k_{t-1}+k_{t} .
$$

We substitute the constraint into the objective function, thus the social planner solves

$$
\max _{k_{t+1}} E \sum_{t=0}^{\infty} \beta^{t} u\left(f\left(k_{t}\right)+(1-\delta) k_{t}-k_{t+1}-f\left(k_{t-1}\right)-(1-\delta) k_{t-1}+k_{t}\right) .
$$

This can be done under the condition that there is an interior solution to the above problem. Having linear utility corner solutions could be an issue. However, the social planner approach unites maximization of households and firms. Even though utility is linear with $\lambda>1$, the production function is concave and hence the social planner chooses an interior solution.

The stochastic Euler equation has the following form

$$
\frac{\partial u\left(\Delta c_{t}\right)}{\partial \Delta c_{t}}=E_{t}\left\{\begin{array}{c}
\beta \frac{\partial u\left(\Delta c_{t+1}\right)}{\partial \Delta c_{t+1}}\left(\frac{\partial f\left(k_{t+1}\right)}{\partial k_{t+1}}+(1-\delta)+1\right) \\
-\beta^{2} \frac{\partial u\left(\Delta c_{t+2}\right)}{\partial \Delta c_{t+2}}\left(\frac{\partial f\left(k_{t+1}\right)}{\partial k_{t+1}}+(1-\delta)\right)
\end{array}\right\} .
$$

The Euler equation obtained here deviates from the standard equation obtained in a stochastic Cass-Koopmans-Ramsey model. Consumption is no longer time-separable since the objective function is now dependent not only on $c_{t}$ and $c_{t+1}$, but also on $c_{t+2}$. Previous decisions about consumption and capital move the reference point and this influences current and future expected utility. Thus, current marginal utility is compared not only to marginal utility in the next period but also to marginal utility thereafter.

The stochastic Euler equation is now the main focus of our investigation. Hansen and Singleton (1982) introduce the concept of testing the implications of stochastic Euler equations directly, using Generalized Method of Moments. 
One advantage of GMM is that it does not require full specification of the underlying economy. It is an econometric estimation procedure where it is possible to estimate parameters in dynamic objective functions without explicitly having to solve for the stochastic equilibrium. GMM estimation allows us to derive parameter estimation of the stochastic Euler equation and to test for overidentification.

We must perform some reformulation of the above Euler equation in order to apply GMM. Our utility function has to be a continuously differentiable function which can be represented by just one function for the entire set of gains and losses. As we note above, our utility function in (4) is not differentiable at the reference point. In order to perform GMM we have to smooth it so that it will also be differentiable at the kink. We achieve this by transforming the utility function in such a way that the loss aversion coefficient and the utility part form an entity. This can be done by setting up the loss aversion coefficient as a switching function. Under the assumption of loss aversion, $\lambda$ in equation (4) should be greater than 1 in the loss area and exactly 1 in the gains area. Its value should switch as close as possible to the reference point. Such a switching function for the loss aversion coefficient $\lambda$ can be represented by

$$
\tilde{f}(x)=1+\frac{\gamma}{1+e^{\mu x}},
$$

where plotting the function, $\tilde{f}(x) \in[1, \gamma+1]$ and $\mu$ represents the speed of switching.

Figure 1 and 2 show the relationship. The higher $\mu$ the faster the switching around zero. The higher $\gamma$ the higher the value range of the loss aversion coefficient $\lambda$.

Equation (10) yields a smooth function to express the loss aversion coefficient $\lambda$ in our model. Now we want to substitute the above switching function (10) for $\lambda$ in the piecewise-linear utility function (4). Plugging equation (10) into equation (4) yields for all $x$ representing $\Delta c$

$$
\hat{f}(x)=x\left(1+\frac{\gamma}{1+e^{\mu x}}\right) .
$$

The graph of equation (11) is shown in Figure 3.

This prospect utility function in Figure 3 has a similar shape to our first specified piecewise-linear utility function in equation (4). However, since we 


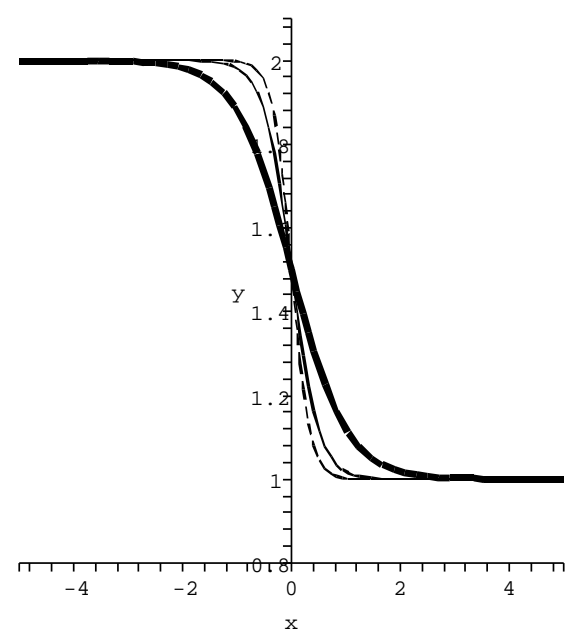

Figure 1: $\mu$ responsible for the switching speed around the reference point with $\mu=2$ (bold line), $\mu=4$ (solid line) and $\mu=6$ (dashed line).

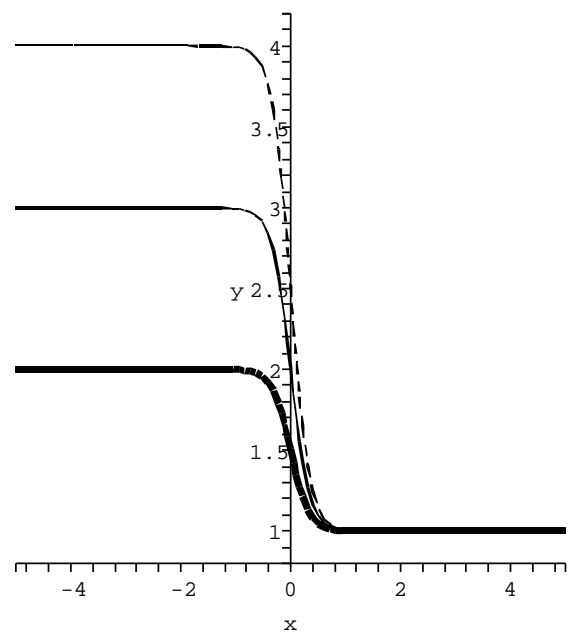

Figure 2: $\gamma$ assigning the interval of the loss aversion coefficient $\lambda$ with $\gamma=1$ (bold line), $\gamma=2$ (solid line) and $\gamma=3$ (dashed line). 


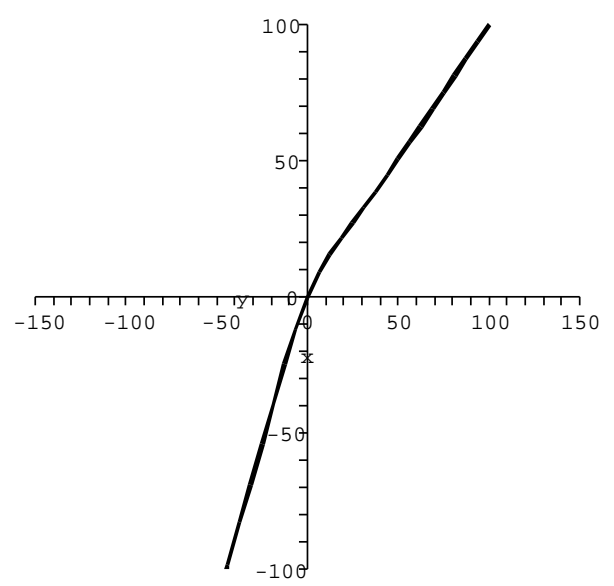

Figure 3: A continuously differentiable prospect utility function with $\gamma=$ 1.25 and $\mu=0.1$.

replace the loss aversion coefficient by the switching function we obtain a continuously twice differentiable utility function.

Differentiation of equation (11) is needed for rewriting the Euler equation:

$$
\hat{f}^{\prime}(x)=1+\frac{\gamma}{1+e^{\mu x}}-\frac{x \gamma \mu e^{\mu x}}{\left(1+e^{\mu x}\right)^{2}} .
$$

Setting $x=\Delta c$ it follows from equation (4) and (11)

$$
\hat{u}(\Delta c)=(\Delta c)\left(1+\frac{\gamma}{1+e^{\mu(\Delta c)}}\right)
$$

and from equation (4), (11) and (12)

$$
\hat{u}^{\prime}(\Delta c)=1+\frac{\gamma}{1+e^{\mu(\Delta c)}}-\frac{(\Delta c) \gamma \mu e^{\mu(\Delta c)}}{\left(1+e^{\mu(\Delta c)}\right)^{2}} .
$$


Plugging equation (14) into the Euler equation yields

$$
\begin{aligned}
& 1+\frac{\gamma}{1+e^{\mu\left(\Delta c_{t}\right)}}-\frac{\left(\Delta c_{t}\right) \gamma \mu e^{\mu\left(\Delta c_{t}\right)}}{\left(1+e^{\mu\left(\Delta c_{t}\right)}\right)^{2}}= \\
& E_{t}\left\{\begin{array}{c}
\beta\left(1+\frac{\gamma}{1+e^{\mu\left(\Delta c_{t+1}\right)}}-\frac{\left(\Delta c_{t+1}\right) \gamma \mu e^{\mu\left(\Delta c_{t+1}\right)}}{\left(1+e^{\mu\left(\Delta c_{t+1}\right)}\right)^{2}}\right)\left(\frac{\partial f\left(k_{t+1}\right)}{\partial k_{t+1}}+(1-\delta)+1\right) \\
-\beta^{2}\left(1+\frac{\gamma}{1+e^{\mu\left(\Delta c_{t+2}\right)}}-\frac{\left(\Delta c_{t+2}\right) \gamma \mu e^{\mu\left(\Delta c_{t+2}\right)}}{\left(1+e^{\mu\left(\Delta c_{t+2}\right)}\right)^{2}}\right)\left(\frac{\partial f\left(k_{t+1}\right)}{\partial k_{t+1}}+(1-\delta)\right)
\end{array}\right\} .
\end{aligned}
$$

This is the form we need in order to apply GMM.

In the following estimations our objective is to test whether a model of loss aversion fits the data. Loss aversion in our Euler equation is represented by $\gamma$, respectively, loss aversion is calculated as $\lambda=1+\gamma$. Setting $\gamma=0$ in the above Euler equation (15), respectively $\lambda=1$ yields

$$
\frac{1}{\beta}=E_{t}\left(\frac{\partial f\left(k_{t+1}\right)}{\partial k_{t+1}}+(1-\delta)\right) \text {. }
$$

This is the first order condition of the corresponding Cass-Koopmans-Ramsey model with linear utility. ${ }^{3}$ Thus, testing for $\gamma$ is also an implicit test against/for the standard Ramsey model.

\section{GMM Estimation Results}

We use quarterly U.S. time series from the OECD data basis, i.e. figures on personal consumption expenditure, gross domestic product and gross capital formation as a proxy for the capital stock. All of the data is real data using prices for the year 2000 and is seasonally adjusted. To convert the data into an intensive form we use quarterly data on civilian employment of persons aged sixteen years and over, provided by the U.S. Department of Labor, Bureau of Labor Statistics. The data covers the period from $1955 Q 1$ to $2004 Q 4$ and is adjusted automatically in the empirical estimations.

Assuming a Cobb-Douglas production function, the uncertainty in our model stems from the production part of the economy. To derive technological shocks, we calculate the Solow residual from the data. This is then used as the technological shock in our Euler equation. The production function is

$$
F\left(A_{t} K_{t}, L_{t}\right)=Y_{t}=A_{t} K_{t}^{\alpha} L_{t}^{1-\alpha}
$$

\footnotetext{
${ }^{3}$ See also Rosenblatt-Wisch (2005).
} 
and in intensive form, dividing by $L_{t}$, we obtain

$$
f\left(k_{t}\right)=y_{t}=A_{t} k_{t}^{\alpha},
$$

where $y_{t}=Y_{t} / L_{t}$ and $k_{t}=K_{t} / L_{t}$. Taking logs and first differences, the Solow residual can then be expressed as

$$
\Delta \ln \left(A_{t}\right)=\Delta \ln \left(y_{t}\right)-\Delta \alpha \ln \left(k_{t}\right) .
$$

$\alpha$ represents the capital share in the production function. A common value assumed is $\alpha=0.33{ }^{4}$ This value is used in our estimations. As in Figure 3, we set $\mu=0.1$ for computational efficiency. This does not influence the results since the observed consumption differences average 244 USD in absolute terms on a quarterly basis, and are correspondingly higher on a half-yearly or yearly basis. All of these values differ considerably from the reference point, which is zero. Therefore a switching speed of $\mu=0.1$ is sufficiently precise and compatible with computational speed. The depreciation rate is set to $\delta=1 .^{5}$ Introducing the Cobb-Douglas type production function into the Euler equation and setting the depreciation rate $\delta=1$ yields:

$$
\begin{aligned}
1+ & \frac{\gamma}{1+e^{\mu\left(\Delta c_{t}\right)}}-\frac{\left(\Delta c_{t}\right) \gamma \mu e^{\mu\left(\Delta c_{t}\right)}}{\left(1+e^{\mu\left(\Delta c_{t}\right)}\right)^{2}}= \\
& E_{t}\left\{\begin{array}{c}
\beta\left(1+\frac{\gamma}{1+e^{\mu\left(\Delta c_{t+1}\right)}}-\frac{\left(\Delta c_{t+1}\right) \gamma \mu e^{\mu\left(\Delta c_{t+1}\right)}}{\left(1+e^{\mu\left(\Delta c_{t+1}\right)}\right)^{2}}\right)\left(\alpha A_{t+1} k_{t+1}^{(\alpha-1)}+1\right) \\
-\beta^{2}\left(1+\frac{\gamma}{1+e^{\mu\left(\Delta c_{t+2}\right)}}-\frac{\left(\Delta c_{t+2}\right) \gamma \mu e^{\mu\left(\Delta c_{t+2}\right)}}{\left(1+e^{\mu\left(\Delta c_{t+2}\right)}\right)^{2}}\right)\left(\alpha A_{t+1} k_{t+1}^{(\alpha-1)}\right)
\end{array}\right\} .
\end{aligned}
$$

Our estimations will be built on this Euler equation. In macroeconomic time series, it is common for error terms to be autocorrelated over time. For this reason, our default setting is the Bartlett kernel, Newey and West's fixed bandwidth (4) and no prewithening. This setting ensures a heteroscedastic and autocorrelation consistent weighting matrix for heteroscedastic and autocorrelated error terms of unknown form. The Bartlett kernel yields a positive semi-definite estimator of the covariance matrix. In general, GMM requires a positive, semi-definite covariance matrix estimator. Negative variance estimates are not desired and also problematic in the sense of convergence to

\footnotetext{
${ }^{4}$ See for example Abel and Bernanke (2001) or Hall and Taylor (1997).

${ }^{5}$ The depreciation rate enters the calculations of the capital formation stock data (OECD basis) and is as such a part of our physical capital available in the production process.
} 
a negative variance. ${ }^{6}$ Further, as is often the case in macroeconomic time series, we perform our empirical investigation in small samples. Hansen, Heaton and Yaron's (1996) simultaneous updating procedure of the weighting matrix and the coefficients is particularly applicable for small sample estimation. This procedure implies convergence after a few iterations, such that the criterion function is minimized.

An advantage of GMM estimation is that we do not have to know, nor to specify, the full economic setting of the underlying economy. Nevertheless, a few assumptions have to be made. GMM relies on the stationarity of the components. Plotting our consumption series, we can already guess that

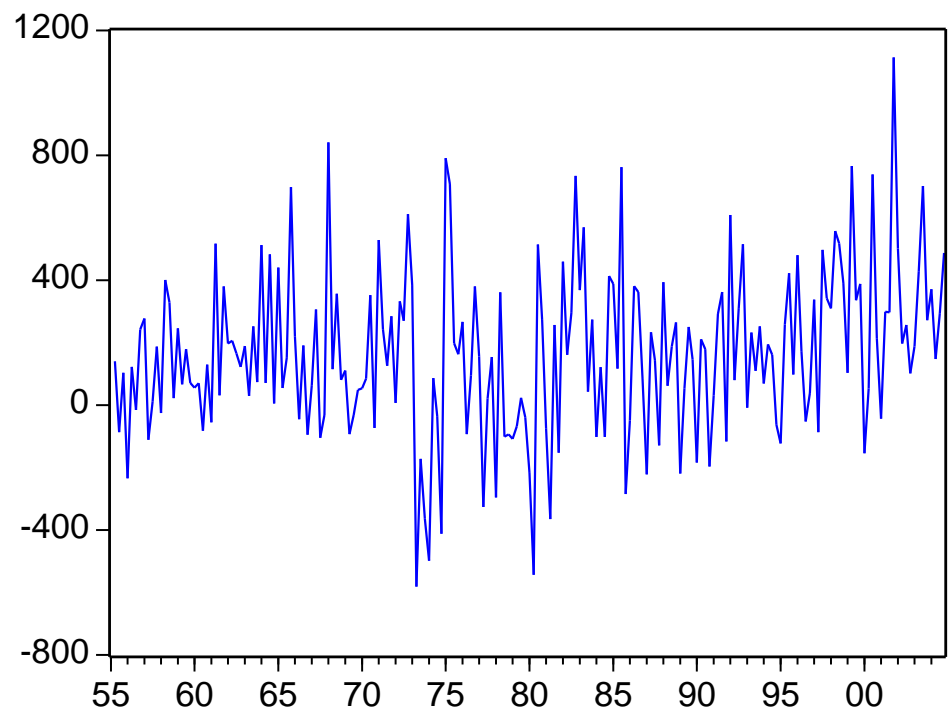

Figure 4: First difference consumption series with quarterly update.

what we have here is first difference stationary. We provide a graph of the first difference consumption path in Figure 4.

To this series we apply the Dickey-Fuller test which does not imply a unit root. In addition, performing the Kwiatowski-Phillips-Schmidt-Shin test for stationarity, the null hypothesis of stationarity cannot be rejected at the $1 \%$ level at least for all lagged consumption series used in the following estimations. Taking the exponential of the Solow residual (Figure 5) in terms of

\footnotetext{
${ }^{6}$ See Mátyás (1999), p. 69 and 77 et seq.
} 
growth rates for technological progress multiplied by the marginal productivity of the growth rate of capital, we obtain a stationary process for the production part of our Euler equation.

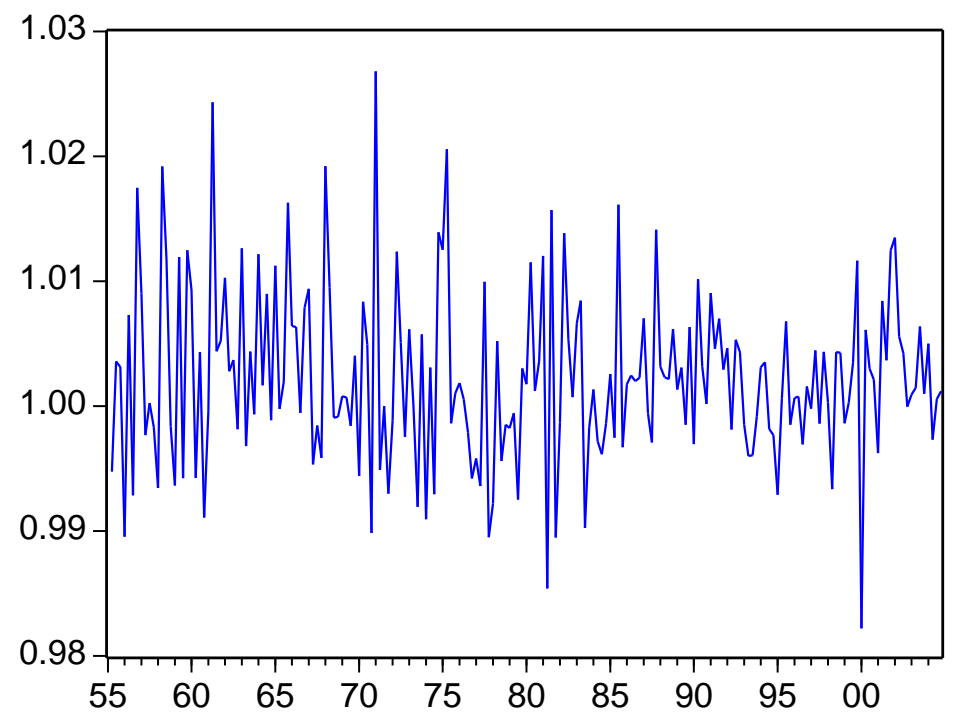

Figure 5: The exponential of the Solow residual.

As mentioned above, we set the rate of capital share of output to $\alpha=0.33$. We run the regression for different discount factors, $\beta$.

As defined in equation (4) our prospect maximizer derives his utility from differences in consumption. He updates the reference point dynamically. But the question is, which reference point from the past will he use? It could well be, that his reference point is updated quarterly. However, this time horizon may be too short and he may opt for the consumption level he had a year ago instead. We therefore run our estimations for different reference updating horizons. We constantly check for continuous stationarity in the series. This is given in all the variations of the reference point and also in the production part of the Euler equation.

We assume that our model is just identified. It has one parameter, $\gamma$, which needs to be estimated, and one equation. Thus, by definition, the J-statistic is 0 . Otherwise, taking instrumental variables into account, the J-statistic is approximately $\chi^{2}$-distributed in a correctly specified model. 
In Table 1 we test for different discount factors and different adjustment of the reference point. All results are significant at the 1\%, respectively $5 \%$ level. It is interesting to note that the further back in the past the adjustment of the reference point is, the higher the estimated value of $\gamma$ and, accordingly, the higher the loss aversion coefficient. This can be explained by the fact that the longer the time period is, the higher the variation in the consumption difference. The variation in consumption increases, whereas the capital path remains unchanged. In our prospect utility function, a higher loss aversion coefficient generally increases the status quo bias. This is inherent in the prospect utility function, as losses loom larger than gains. Thus, falling short of the reference point will do more harm than exceeding it by the same amount. As such, we can interpret the capital stock path as the given status quo. When extending the reference point lag structure of consumption, the status quo is still given by the capital stock, and in order to replicate this capital stock data when the variation in consumption data increases, a higher loss aversion coefficient is needed. Thus, the result is in line with the generally observable status quo effect of the prospect utility function. It is important to note that by referring to equation (10), the loss aversion coefficient can be approximately calculated by $(1+\gamma)$. For the more frequent updating procedure, we see that the estimated $\gamma$ is more significant, which could be an indication of more substantial evidence that the consumption reference point is updated more frequently. The pattern is similar for all values of $\beta$. Comparing the $\gamma$ values of the same lag structure for the different discount factors $\beta$, i.e. reading the columns in Table 1 , we note that the higher the discount factor, the lower the loss aversion implied by the data. This means that, when fixing a data point, one effect is obtained from the loss aversion part, while the other is attributable to the discount factor. This is in line with the results obtained by Rosenblatt-Wisch and Schenk-Hoppé (2005), where a deterministic version of a prospect utility maximizer is discussed. Rosenblatt-Wisch and Schenk-Hoppé note that the $\beta$ and the loss aversion coefficient work in the same direction - the higher the discount factor (or the loss aversion coefficient), the more future losses hurt. Thus, if we fix a given consumption/ capital path, there will be two forces at work which make future losses more crucial. One of these forces is a higher loss aversion coefficient, while the other is a higher $\beta$. Thus, it is not surprising that, ceteris paribus, if one component is lowered, the other will have to be increased (and vice versa), in order to explain a given consumption/ capital path.

Following up the above calculations we use instrumental variables to per- 


\begin{tabular}{c|c|c|c}
\hline Reference point adjustment & 1 quarter & 2 quarters & 4 quarters \\
\hline \hline$\beta=0.90$ & & & \\
$\gamma$ & $0.8517^{*}$ & $1.2958^{*}$ & $3.2653^{* *}$ \\
Standard Dev. & 0.1223 & 0.2623 & 1.2955 \\
J-stats & 0 & 0 & 0 \\
$\beta=0.95$ & & & \\
$\gamma$ & $0.5283^{*}$ & $0.7883^{*}$ & $1.9063^{* *}$ \\
Standard Dev. & 0.0930 & 0.1844 & 0.8124 \\
J-stats & 0 & 0 & 0 \\
\hline$\beta=0.97$ & & & \\
$\gamma$ & $0.3830^{*}$ & $0.5656^{*}$ & $1.3306^{* *}$ \\
Standard Dev. & 0.0808 & 0.1525 & 0.6018 \\
J-stats & 0 & 0 & 0 \\
\hline$* / * *$ denote statistical significance at the $1 \%$, respectively $5 \%$ level.
\end{tabular}

Table 1: Estimates of $\gamma$ for different discount factors and different adjustment of the reference point in a just identified system.

form further estimations. It is always questionable which instruments should be used, and the results can be very sensitive to the set of instruments. This is also the case in the following estimations. Table 2 displays the calculations using the first lagged values of the related consumption difference as instrumental variables, while Table 3 shows the calculations for the first lagged value of capital growth. We check whether the overidentifying restrictions hold by calculating the J-statistics with the related p-values.

As discussed above, both tables indicate a similar pattern. For a given reference updating scheme, the higher the $\beta$ the lower the corresponding loss aversion value. Reading the rows in the tables, we again see that the more time elapses between updating the reference point, the higher the loss aversion. However, we observe some deviation in the '2 quarters' column in Table 2 , where $\gamma$ is too small for $\beta=0.97$ as compared to the pattern in Table 1. The corresponding J-statistic and p-value in Table 2 indicate that the overidentifying restrictions for this specification do not hold at the $1 \%$ level. The model appears to be misspecified. In this case, the estimated value of $\gamma$ and its significance is spurious. As for the other estimation results in Table 2 , the J-statistics and p-values reflect the fact that the overidentifying restrictions hold at the $1 \%$ level and the model cannot be rejected as such. 
Nevertheless, with respect to the stability of the model, we note that the higher the p-values, the more explanatory power our model displays.

\begin{tabular}{c|c|c|c}
\hline Reference point adjustment & 1 quarter & 2 quarters & 4 quarters \\
\hline \hline$\beta=0.90$ & & & \\
$\gamma$ & $0.8892^{*}$ & $1.1745^{*}$ & $2.9759^{* *}$ \\
Standard Dev. & 0.1313 & 0.2376 & 1.1927 \\
J-stats & 0.0624 & 3.3717 & 4.4977 \\
p-value & 0.8028 & 0.0663 & 0.0339 \\
\hline$\beta=0.95$ & & & \\
$\gamma$ & $0.5560^{*}$ & $0.6140^{*}$ & $1.9152^{* *}$ \\
Standard Dev. & 0.1005 & 0.1444 & 0.8217 \\
J-stats & 0.1426 & 5.2114 & 1.5187 \\
p-value & 0.7057 & 0.0224 & 0.2178 \\
\hline$\beta=0.97$ & & & \\
$\gamma$ & $0.4058^{*}$ & $0.3493^{*}$ & $1.3817^{* *}$ \\
Standard Dev. & 0.0879 & 0.0955 & 0.6217 \\
J-stats & 0.2006 & 7.1087 & 0.4206 \\
p-value & 0.6542 & 0.0077 & 0.5167 \\
\hline * $/ * *$ denote statistical significance at the $1 \%$, respectively $5 \%$ level.
\end{tabular}

Table 2: Estimates of $\gamma$ for different discount factors and different adjustment of the reference point with the first lagged value of consumption difference as instrumental variable.

For example, a p-value of $50 \%$ indicates that the model would be incorrectly rejected in $50 \%$ of cases, even though the specifications are correct. As already mentioned, for certain specifications our p-values are such that we cannot reject the null hypothesis of a $\chi^{2}$-distributed J-statistic at a common significance level. However, for half-yearly updating in Table 2, our p-values are rather small and in Table 3 we do not find any p-values above $50 \%$. Overall, Table 2 displays higher p-values than Table 3. With reference point updating of 1 quarter and all three discount factors $\beta$, the $\mathrm{p}$-values are strikingly high and the estimated values of $\gamma$ are significant at the $1 \%$ level and positive. An annual updating scheme for $\beta=0.97$ also yields a respectable p-value above $50 \%$ as well as a positive and significant $\gamma$ at the $5 \%$ level. This is evidence that loss aversion can indeed be found in the data, in particular, if the point of reference is updated quarterly or annually. 
The results of Table 2 would also be in line with common everyday analysis, where commentary usually relates to quarterly or year-on-year data on consumption and consumption growth

A loss aversion parameter close to Kahneman and Tversky's experimentally supported value of 2.25 is generated by an annual reference point updating scheme with a discount factor of $\beta=0.97$ and the corresponding $\gamma=1.3817$.

It is not surprising that the results in Table 2 and 3 are relatively unconvincing, since the explanatory power of capital growth and lagged consumption differences with respect to the consumption path and the capital path is low, thus making them weak instruments. For this reason, the results will not improve if we use as lagged variables a mix of capital and consumption or include more lagged values of each. On the contrary. If we do this, the weak instrument problem will be aggravated. This is shown in the Appendix. If we use lagged values of consumption alone, the model for a one-quarter or one-year updating scheme appears to be favorable. Nevertheless, all estimations show the same patterns as described above. With a rise in the loss aversion coefficient, the updating of the point of reference moves further back in the past and the discount factor $\beta$ decreases. These patterns persist irrespective of the above described arguments with respect to the significance of the model or possible misspecifications.

GMM is an approach which makes it possible to estimate a model directly from its first order conditions. As such, it has not been free of criticism due to the fact that it tests the necessary but not the sufficient conditions of optimality. Nevertheless, it has been widely used to obtain empirical implications from first order conditions. In macroeconomic models, particularly, we often encounter the problem of small sample bias. To handle this bias, we have used Hansen, Heaton and Yaron's suggested iteration scheme for the weighting function.

For the model which is just identified, as well as for the overidentified model with the first lagged value of consumption difference as the instrumental variable (Table 2), we find strong evidence of a positive $\gamma$ resulting in a loss aversion coefficient $\lambda>1$. We come close to Kahneman and Tversky's loss aversion coefficient value of 2.25 for an annual updating scheme and a discount factor of 0.97. All estimated values for $\gamma$ are significantly different from zero and positive. This is a strong indication against the standard Ramsey model and in favor of incorporating loss aversion to fit the data better. 


\begin{tabular}{c|c|c|c}
\hline Reference point adjustment & 1 quarter & 2 quarters & 4 quarters \\
\hline \hline$\beta=0.90$ & & & \\
$\gamma$ & $0.7820^{*}$ & $1.1613^{*}$ & $2.9390^{* *}$ \\
Standard Dev. & 0.1142 & 0.2343 & 1.1690 \\
J-stats & 9.6104 & 3.4938 & 2.3157 \\
p-value & 0.0082 & 0.1743 & 0.3142 \\
\hline$\beta=0.95$ & & & \\
$\gamma$ & $0.3981^{*}$ & $0.6817^{*}$ & $1.5881^{* *}$ \\
Standard Dev. & 0.0748 & 0.1607 & 0.6743 \\
J-stats & 11.6702 & 2.9330 & 2.5086 \\
p-value & 0.0029 & 0.2307 & 0.2853 \\
\hline$\beta=0.97$ & & & \\
$\gamma$ & $0.1931^{*}$ & $0.4711^{*}$ & $1.0285^{* *}$ \\
Standard Dev. & 0.0468 & 0.1299 & 0.4698 \\
J-stats & 16.2270 & 2.5940 & 2.6411 \\
p-value & 0.0003 & 0.2734 & 0.2670 \\
\hline
\end{tabular}

$* / * *$ denote statistical significance at the $1 \%$, respectively $5 \%$ level.

Table 3: Estimates of $\gamma$ for different discount factors and different adjustment of the reference point with the first lagged value of capital growth as instrumental variable.

\section{Conclusion}

We introduced prospect theory into a neoclassical growth model and derived an intertemporal Euler equation which is defined not only by comparing the current marginal utility of consumption today to the marginal utility tomorrow, but also to the marginal utility the day after tomorrow. Our aim was to link the prospect utility Euler equation to real economic data and investigate whether the loss aversion parameter can be identified in macroeconomic time series. To achieve this, we linearized Kahneman and Tversky's power function and represented the loss aversion parameter by a switching function. As such, our piecewise-linear utility function is differentiable even at the reference point. We needed to find a representation of the utility function which was the same for both gains and losses in order to make the Euler equation testable under GMM.

Our GMM estimation results indicate that the higher we set the discount factor, the lower the loss aversion found in the data. This is consistent with 
the theoretical and numerical results we obtain from a deterministic prospect utility growth model where we observe complementarity of the discount factor and the loss aversion coefficient. ${ }^{7}$ We observe a loss aversion parameter $\lambda>1$, which increases as the updating horizon becomes longer. This is an expression of the inherent status quo bias. In particular, we find strong evidence of loss aversion with a quarterly and annual updating of the point of reference. Furthermore, the loss aversion coefficient comes close to Kahneman and Tversky's experimentally validated value of 2.25 for a representative agent, who sets his reference point annually and whose discount factor is approximately 0.97 . Thus, even with a linearized version of our prospect Euler equation we can empirically reconcile Kahneman and Tversky's findings of loss aversion and thinking in differences with the macroeconomic theory of growth.

\footnotetext{
${ }^{7}$ See Rosenblatt-Wisch and Schenk-Hoppé (2005).
} 


\section{Appendix}

The appendix presents further estimations with instrumental variables for which we use combinations of the instrumental variables already discussed in this text. Again, estimation results indicate that the overidentifying restrictions hold for most updating schemes at the $1 \%$ level, but that p-values are relatively low (all below 40\%). This stems from the weak instruments used. However, the common pattern first observed in Table 1 continues to hold in general, namely that the more time elapses before the reference point is updated, the higher the loss aversion found in the data. Also, the higher the discount factor, the lower the loss aversion parameter. In addition, all estimations yield a loss aversion coefficient, $1+\gamma>1$.

\begin{tabular}{c|c|c|c}
\hline Reference point adjustment & 1 quarter & 2 quarters & 4 quarters \\
\hline \hline$\beta=0.90$ & & & \\
$\gamma$ & $0.8058^{*}$ & $1.0864^{*}$ & $2.8210^{* *}$ \\
Standard Dev. & 0.1202 & 0.2188 & 1.1252 \\
J-stats & 8.5800 & 6.3206 & 5.4840 \\
p-value & 0.0137 & 0.0424 & 0.0644 \\
\hline$\beta=0.95$ & & & \\
$\gamma$ & $0.4258^{*}$ & $0.5648^{*}$ & $1.6804^{* *}$ \\
Standard Dev. & 0.2188 & 0.1331 & 0.7048 \\
J-stats & 10.3084 & 7.2800 & 3.2249 \\
p-value & 0.0058 & 0.0263 & 0.1994 \\
$\beta=0.97$ & & & \\
$\gamma$ & $0.2278^{*}$ & $0.3217^{*}$ & $1.1214^{* *}$ \\
Standard Dev. & 0.0545 & 0.0884 & 0.4860 \\
J-stats & 13.6692 & 8.8538 & 2.5551 \\
p-value & 0.0011 & 0.0120 & 0.2787 \\
\hline
\end{tabular}

$* / * *$ denote statistical significance at the $1 \%$, respectively $5 \%$ level.

Table 4: Estimates of $\gamma$ for different discount factors and different adjustment of the reference point with the first lagged values of consumption difference and capital growth as instrumental variables. 


\begin{tabular}{c|c|c|c}
\hline Reference point adjustment & 1 quarter & 2 quarters & 4 quarters \\
\hline \hline$\beta=0.90$ & & & \\
$\gamma$ & $0.8636^{*}$ & $1.2104^{*}$ & $2.9760^{* *}$ \\
Standard Dev. & 0.1302 & 0.2492 & 1.1568 \\
J-stats & 4.5472 & 12.5426 & 6.7953 \\
p-value & 0.2081 & 0.0057 & 0.0787 \\
$\beta=0.95$ & & & \\
$\gamma$ & $0.5217^{*}$ & $0.3695^{*}$ & $1.8517^{* *}$ \\
Standard Dev. & 0.0980 & 0.0950 & 0.7626 \\
J-stats & 4.2463 & 21.3113 & 4.1921 \\
p-value & 0.2361 & 0.0001 & 0.2414 \\
\hline$\beta=0.97$ & & & \\
$\gamma$ & $0.3606^{*}$ & $0.0366^{*}$ & $1.2774^{* *}$ \\
Standard Dev. & 0.0830 & 0.0116 & 0.5476 \\
J-stats & 4.2640 & 38.2746 & 3.0452 \\
p-value & 0.2343 & 0.0000 & 0.3847 \\
\hline * ${ }^{* *}$ denote statistical significance at the $1 \%$, respectively $5 \%$ level.
\end{tabular}

Table 5: Estimates of $\gamma$ for different discount factors and different adjustment of the reference point with the first, second and third lagged values of consumption difference as instrumental variables. 


\section{References}

[1] Aït-Sahalia, Yacine and Brandt, Michael W. (2001): "Variable Selection for Portfolio Choice," The Journal of Finance, 56, 1297-1351.

[2] Alonso-Carrera, Jaime, Caballé, Jordi and Raurich, Xavier (2005): "Growth, Habit Formation, and Catching-up with the Joneses," European Economic Review, 49, 1665-1691.

[3] Barro, Robert J. (1999): "Ramsey Meets Laibson in the Neoclassical Growth Model," Quarterly Journal of Economics, 114, 1125-1152.

[4] Boyer, Marcel (1978): "A Habit Forming Optimal Growth Model," International Economic Review, 19, 585-609.

[5] Cass, David (1965): "Optimum Growth in an Aggregative Model of Capital Accumulation," Review of Economic Studies, 32, 223-240.

[6] Cochraine, John H. (2001): "Asset Pricing," New Jersey: Princeton University Press.

[7] De la Croix, David (2001): "Growth Dynamics and Education Spending: The Role of Inherited Tastes and Abilities," European Economic Review, 45, 1415-1438.

[8] De la Croix, David and Michel, Philippe (1999): "Optimal Growth when Tastes Are Inherited," Journal of Economic Dynamics and Control, 23, 519-537.

[9] Hamilton, James D. (1994): "Time Series Analysis," New Jersey: Princeton University Press.

[10] Hansen, Lars P. (1982): "Large Sample Properties of Generalized Method of Moments Estimators," Econometrica, 50, 1029-1054.

[11] Hansen, Lars P., Heaton, John and Yaron, Amir (1996): "Finite-Sample Properties of Some Alternative GMM Estimators," Journal of Business and Economic Statistics, 14, 262-280.

[12] Hansen, Lars P. and Singleton, Kenneth J. (1982): "Generalized Instrumental Variables Estimation of Nonlinear Rational Expectations Models," Econometrica, 50, 1269-1286. 
[13] Kahneman, Daniel and Tversky, Amos (1979): "Prospect Theory: An Analysis of Decisions Under Risk," Econometrica, 47, 263-291.

[14] Koopmans, Tjalling C. (1960): "Stationary Ordinal Utility and Impatience," Econometrica, 28, 287-309.

[15] Koopmans, Tjalling C. (1965): "On the Concept of Optimal Economic Growth," in: The Econometric Approach to Development Planning, Chicago: Rand-McNally.

[16] Kwiatkowski, Denis, Phillips, Peter C. B., Schmidt, Peter and Shin, Yongcheol (1992): "Testing the Null Hypothesis of Stationarity against the Alternative of a Unit Root : How Sure Are We that Economic Time Series Have a Unit Root?," Journal of Econometrics, 54, 159-178.

[17] Laibson, David (1997): "Golden Eggs and Hyperbolic Discounting," Quarterly Journal of Economics, 112, 443-477.

[18] Mátyás, László (1999): "Generalized Method of Moments Estimation," Cambridge: Cambridge University Press.

[19] Mausumi, Das (2003): "Optimal Growth with Decreasing Marginal Impatience," Journal of Economic Dynamics and Control, 27, 18811898.

[20] Newey, Whitney K. and West, Kenneth D. (1987): "A Simple Positive Semi-Definite, Heteroscedasticity and Autocorrelation Consistent Covariance Matrix," Econometrica, 55, 703-708.

[21] Ramsey, Frank P. (1928): "A Mathematical Theory of Saving," Economic Journal, 38, 543-559.

[22] Ryder, Harl E. Jr. and Heal, Geoffrey M. (1973): "Optimal Growth with Intertemporally Dependent Preferences," Review of Economic Studies, 40, 1-31.

[23] Rosenblatt-Wisch, Rina (2005): "Optimal Capital Accumulation in a Stochastic Growth Model under Loss Aversion," NCCR FINRISK Working Paper, 222, University of Zurich. 
[24] Rosenblatt-Wisch, Rina and Schenk-Hoppé, Klaus R. (2005): "Consumption Paths under Prospect Utility in an Optimal Growth Model," NCCR FINRISK Working Paper, 237, University of Zurich.

[25] Shi, Shouyong and Epstein, Larry G. (1993): "Habits and Time Preference," International Economic Review, 34, 61-84.

[26] Tversky, Amos and Kahneman, Daniel (1992): "Advances in Prospect Theory: Cumulative Representation of Uncertainty," Journal of Risk and Uncertainty, 5, 297-323.

[27] Uzawa, Hirofumi (1968): "Time Preference, the Consumption Function, and Optimum Asset Holdings," in: Wolfe, J. N. (Ed.), Value, Capital and Growth: Papers in Honour of Sir John Hicks, Edinburgh: Edinburgh University Press. 


\section{Swiss National Bank Working Papers published since 2004:}

2004-1 Samuel Reynard: Financial Market Participation and the Apparent Instability of Money Demand

2004-2 Urs W. Birchler and Diana Hancock: What Does the Yield on Subordinated Bank Debt Measure?

2005-1 Hasan Bakhshi, Hashmat Khan and Barbara Rudolf: The Phillips curve under state-dependent pricing

2005-2 Andreas M. Fischer: On the Inadequacy of Newswire Reports for Empirical Research on Foreign Exchange Interventions

2006-1 Andreas M. Fischer: Measuring Income Elasticity for Swiss Money Demand: What do the Cantons say about Financial Innovation?

2006-2 Charlotte Christiansen and Angelo Ranaldo: Realized Bond-Stock Correlation: Macroeconomic Announcement Effects

2006-3 Martin Brown and Christian Zehnder: Credit Reporting, Relationship Banking, and Loan Repayment

2006-4 Hansjörg Lehmann and Michael Manz: The Exposure of Swiss Banks to Macroeconomic Shocks - an Empirical Investigation

2006-5 Katrin Assenmacher-Wesche and Stefan Gerlach: Money Growth, Output Gaps and Inflation at Low and High Frequency: Spectral Estimates for Switzerland

2006-6 Marlene Amstad and Andreas M. Fischer: Time-Varying Pass-Through from Import Prices to Consumer Prices: Evidence from an Event Study with Real-Time Data

2006-7 Samuel Reynard: Money and the Great Disinflation

2006-8 Urs W. Birchler and Matteo Facchinetti: Can bank supervisors rely on market data? A critical assessment from a Swiss perspective

2006-9 Petra Gerlach-Kristen: A Two-Pillar Phillips Curve for Switzerland

2006-10 Kevin J. Fox and Mathias Zurlinden: On Understanding Sources of Growth and Output Gaps for Switzerland

2006-11 Angelo Ranaldo: Intraday Market Dynamics Around Public Information Arrivals

2007-1 Andreas M. Fischer, Gulzina Isakova and Ulan Termechikov: Do FX traders in Bishkek have similar perceptions to their London colleagues? Survey evidence of market practitioners' views 
2007-2 Ibrahim Chowdhury and Andreas Schabert: Federal Reserve Policy viewed through a Money Supply Lens

2007-3 Angelo Ranaldo: Segmentation and Time-of-Day Patterns in Foreign Exchange Markets

2007-4 Jürg M. Blum: Why `Basel II’ May Need a Leverage Ratio Restriction

2007-5 Samuel Reynard: Maintaining Low Inflation: Money, Interest Rates, and Policy Stance

2007-6 Rina Rosenblatt-Wisch: Loss Aversion in Aggregate Macroeconomic Time Series 
Swiss National Bank Working Papers are also available at www.snb.ch, section Publications/Research Subscriptions or individual issues can be ordered at Swiss National Bank, Fraumünsterstrasse 8, CH-8022 Zurich, fax+41 4463181 14, E-mail library@snb.ch 